\title{
Promoting and maintaining physical activity in the transition to retirement: a systematic review of interventions for adults around retirement age
}

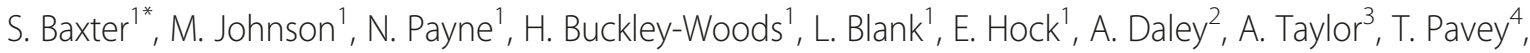 \\ G. Mountain ${ }^{1}$ and E. Goyder ${ }^{1}$
}

\begin{abstract}
It has been argued that transition points in life, such as the approach towards, and early years of retirement present key opportunities for interventions to improve the health of the population. Research has also highlighted inequalities in health status in the retired population and in response to interventions which should be addressed. We aimed to conduct a systematic review to synthesise international evidence on the types and effectiveness of interventions to increase physical activity among people around the time of retirement. A systematic review of literature was carried out between February 2014 and April 2015. Searches were not limited by language or location, but were restricted by date to studies published from 1990 onwards. Methods for identification of relevant studies included electronic database searching, reference list checking, and citation searching. Systematic search of the literature identified 104 papers which described study populations as being older adults. However, we found only one paper which specifically referred to their participants as being around the time of retirement. The intervention approaches for older adults encompassed: training of health care professionals; counselling and advice giving; group sessions; individual training sessions; in-home exercise programmes; in-home computer-delivered programmes; in-home telephone support; in-home diet and exercise programmes; and community-wide initiatives. The majority of papers reported some intervention effect, with evidence of positive outcomes for all types of programmes. A wide range of different measures were used to evaluate effectiveness, many were self-reported and few studies included evaluation of sedentary time. While the retirement transition is considered a significant point of life change, little research has been conducted to assess whether physical activity interventions at this time may be effective in promoting or maintaining activity, or reducing health inequalities. We were unable to find any evidence that the transition to retirement period was, or was not a significant point for intervention. Studies in older adults more generally indicated that a range of interventions might be effective for people around retirement age.
\end{abstract}

Keywords: Physical activity, Retirement, Older age, Exercise, Inequalities, Systematic review, Interventions, Programmes

\footnotetext{
* Correspondence: s.k.baxter@sheffield.ac.uk

'School of Health and Related Research, University of Sheffield, Regent Court,

30 Regent Street, Sheffield S14DA, UK

Full list of author information is available at the end of the article
} 


\section{Background}

With a growing population approaching retirement age there has been an increasing focus on how this sector of society can maintain their independence, and their mental and physical well-being. It has been recognised for some years that a large proportion of people aged over 50 are sedentary (take less than half an hour of moderate intensity physical activity a week), and few take levels of activity recommended for improving health (30 min of moderate physical activity at least five times a week such as brisk walking) [1].

It has been argued that significant points of life change (such as the approach towards, and early years of retirement) present an opportunity for health promotion activities and other interventions $[1,2]$. The transition to retirement may be associated with significant alterations in lifestyle, including change in the level and types of physical activity [PA]. This period of life may therefore be a potentially important time to intervene, to maintain or promote activity in older age $[2,3,4]$. Recent research also suggests that total weekly PA levels after retirement tend to increase in older people from higher socioeconomic groups, but decrease in those from lower socioeconomic groups [1]. There is therefore potential for PA interventions to address widening health inequalities in older age.

A number of previous reviews have examined PA interventions in populations of older adults (over $50 \mathrm{~s}$, over $60 \mathrm{~s}$, over 65 s, 55-75 year olds or older adults generally), or associations between life changes and PA [5-16]. Three previous reviews have specifically considered retirement $[1,16,17]$. The first of these [16] examined health promotion at retirement, the second [1] examined studies which reported associations between exercise and PA in retirement, the third examined five qualitative papers relating to the retirement transition [17]. A table is available as Additional file 1 which details the focus and findings of these reviews.

Our study, in contrast to this existing work, aimed to conduct a systematic review of international evidence on the types and effectiveness of interventions to increase PA among people around the time of retirement. We aimed to examine evidence regarding optimal interventions around this point of life change. Also, we intended to examine the impact of interventions in different populations, and the potential for retirement to increase health inequalities.

\section{Review}

A review protocol was developed prior to beginning the study, and was registered with the PROSPERO database number CRD: 42014007446.

\section{Identification of studies}

A systematic and comprehensive search of electronic databases was undertaken in March 2014 to December
2014. A wide variety of sources were searched in the disciplines of medicine and health, social sciences, and specialist bibliographic databases. The initial search comprised terms to reflect the concept of the transition into retirement, combined with terms to reflect the concept of physical activity. This search retrieved only a limited number of relevant papers, therefore a second search was developed which used broader terms for older age. The databases searched and search strategy are available as Additional file 1.

In addition to electronic database searching, citation searching was undertaken, and searches for grey literature from the UK, together with screening of reference lists of included studies.

All citations were imported into Reference Manager (Version 12) and duplicates deleted. The database of citations was screened at title and abstract level by two members of the team.

Our target population was people during and shortly after the transition to retirement, including those not in paid employment, and those about to leave paid employment. We excluded study populations where the intervention was provided for a specific clinical condition, participants described as being elderly and frail, or with limited mobility. We included studies evaluating any intervention which aimed to increase and/or maintain levels of physical activity. We excluded interventions which were described as aiming to increase stretching/flexibility/balance, or reduce falls.

Outcomes of interest included direct measures of physical activity, indirect measures of physical activity (such as hours of gardening), and relevant social, psychological, behavioural and environmental outcomes. Experimental and observational studies were included. We included studies from any developed country which is a member of the Organisation for Economic Collaboration and Development, as these have the most similar health delivery systems to the UK. We included studies published in English, and those in other languages which provided English abstracts.

\section{Data extraction and synthesis}

Full copies of citations coded as potentially relevant were obtained, and those meeting the inclusion criteria were read in detail and data extracted. Three members of the research team carried out the screening and data extraction. The heterogeneity of the included work precluded summarising the studies via meta-analysis. Review findings were reported instead using narrative synthesis methods, and Harvest Plot techniques [18] to provide a visual summary of intervention effectiveness.

\section{Quality appraisal}

Quality assessment of the effectiveness studies was based on an adaptation of the Cochrane criteria for judging 
risk of bias [19] due to the wide range of study designs. This method classifies studies in terms of sources of potential bias within studies: selection bias; performance bias; attrition bias; detection bias; and reporting bias. The completed assessment for each study is available as Additional file 1.

\section{Results of the review}

From a database of 13,253 citations, 103 papers were included in the review (see Figs. 1 and 2). Within this set of articles we found only one paper [20] which specifically referred to the participants as being recently retired. The literature provided predominantly age bands or average ages for their study populations. Some included numbers in employment/not in employment, and a few included the percentage who were retired. Tables listing papers by population characteristics are available as Additional file 1.

In the absence of literature referring to our target population, we used age as a proxy for the period of retirement transition. We developed a grading system of applicability for the papers, with A1 papers having populations described as recently retired or about to retire $(n=1)$, A2 papers with population mean or median of 55-69 years $(n=63)$, A3i papers had a population mean/median in the range of age 70-75 $(n=30)$, and A3ii papers had a population mean/median of age $49-54(n=9)$. In this article we focus on the A1/A2 studies [20-84].

The literature was of a reasonably high quality in terms of design, with a large proportion $(n=55)$ of the studies using a randomised or cluster randomised design. The most frequent areas of concern were: limited reporting regarding the process of randomisation; the recruitment of volunteer participants; studies having multiple intervention arms with no control condition; the wide use of selfreported data; and in some studies high rates of drop out.

The greatest proportion of work was reported by authors based in the USA $(n=32)$, followed by The Netherlands $(n=12)$ and then Australia/New Zealand $(n=9)$. Around a third of papers $(n=32)$ reported interventions with majority female participants. Few $(n=2)$ studies recruited only males. We identified only one study which described participants as being of predominantly low socio-economic status [61] and one paper in a minority ethnic population [69].

The studies measured a wide range of outcomes (a table of the outcomes reported is provided as Additional file 1). These included self-completed questionnaires (in person, via telephone or postal), outcomes that were measured by the research team (including weight, BMI,
Records identified through database searching ( $\mathrm{n}=4935$ )
Additional records identified through other sources

Citation searching $(\mathrm{n}=103)$

Reference lists $(n=69)$

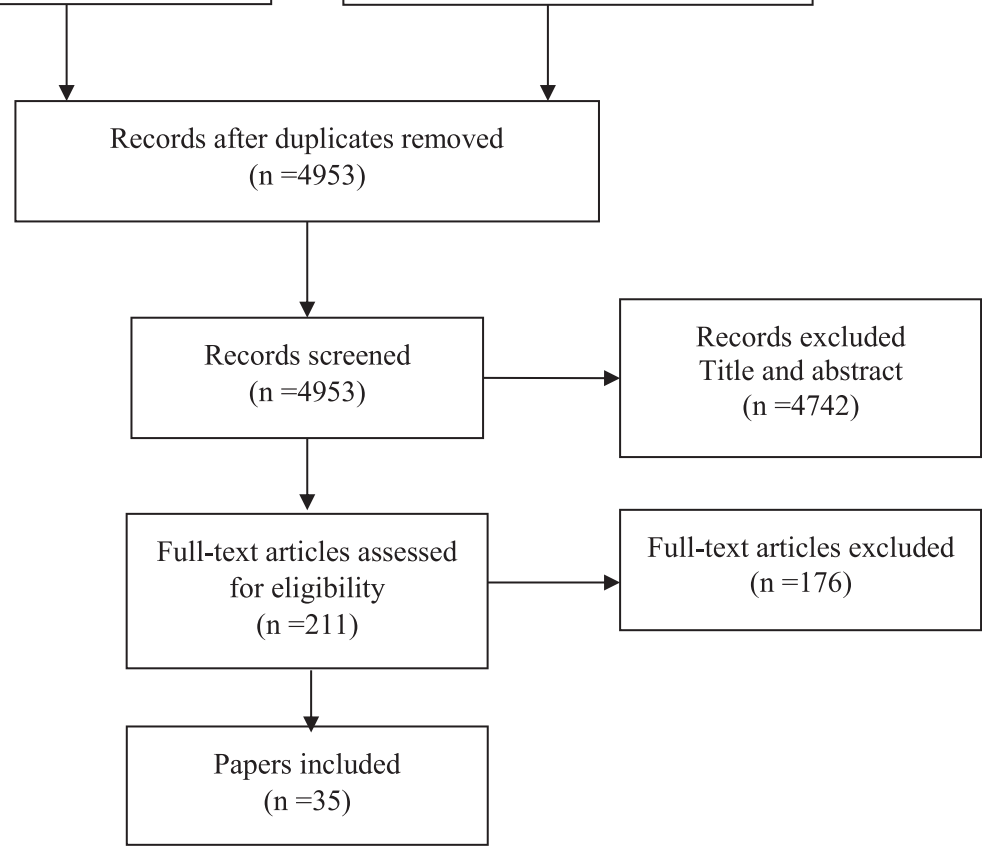

Fig. 1 Process of selection of studies: first search 
Records identified through database searching $(\mathrm{n}=8580)$
Additional records identified through other sources Citation searching $(\mathrm{n}=54)$ Reference lists $(\mathrm{n}=179)$

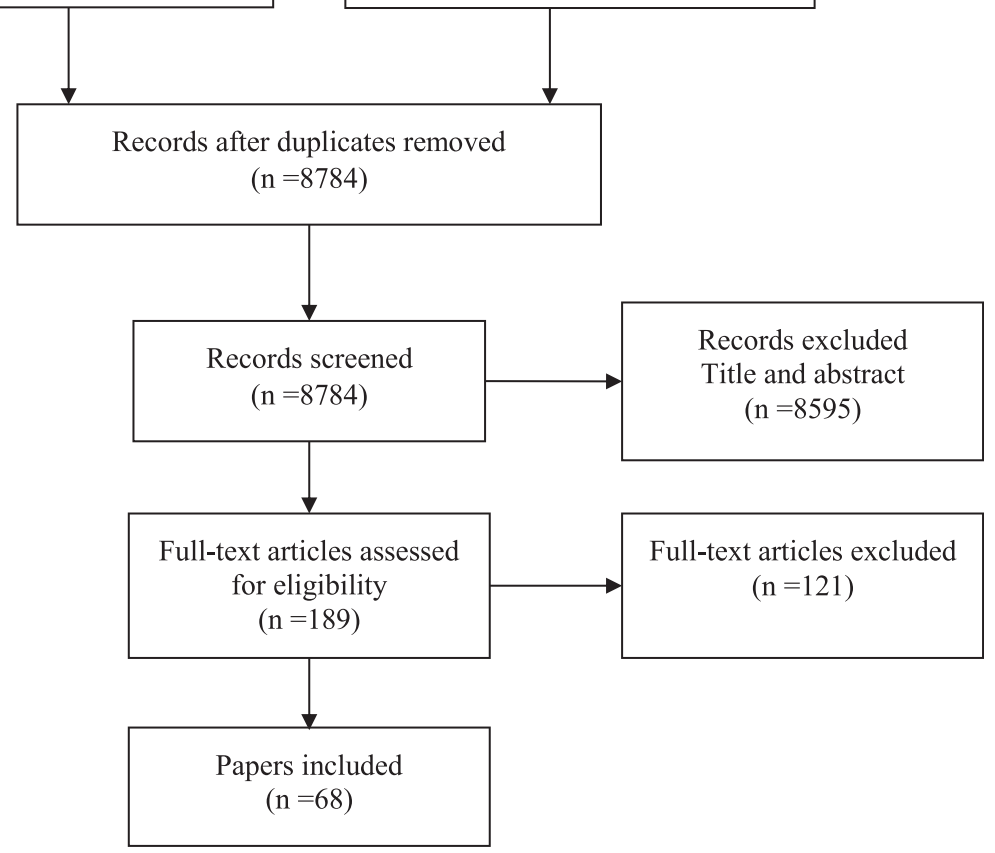

Total papers included from searches one and two Intervention $(\mathrm{n}=103)$

Fig. 2 Process of selection of studies: second search

and fitness tests), together with data downloaded from pedometers or accelerometers. Two papers measured sedentary behaviour in addition to activity $[55,61]$.

The studies reported a varied range of intervention approaches, which we classified into eight typologies. A summary of the characteristics of each study and main findings is available as Additional file 1. The Harvest plots (Fig. 3) provide a visual summary of the reported effectiveness of interventions within each typology. The categorisation as more/less effective was based on the proportion of outcome measures that were significantly different ( $p$ $<0.05$ or $p<0.01$ ), either from baseline to follow up (for those with multiple intervention arms only), or between intervention and control groups. To be considered "more effective", the majority of outcomes (at least half) relating to PA needed to show a positive intervention effect.

In these charts each unique study is represented by a column. The height, shading and pattern of each column indicates the strength of the evidence in terms of type of study design, use or non-use of a comparator arm, and self-reported versus measured outcomes. Studies which can be considered to provide stronger evidence of effectiveness are those with solid black columns. Studies which can be considered to provide weaker evidence of effectiveness are those with grey, dotted columns.

As can be seen from the plots, the evidence regarding effectiveness for the different types of interventions is fairly positive across the set. Strength of evidence is best judged by considering not only volume of papers but also consistency of findings $[18,83]$. Therefore, we outline both volume and consistency of study results below.

\section{Intervention typology Counselling and advice}

Eleven papers (10 studies) assessed the effectiveness of interventions comprising the giving of advice or counselling [21-31]. One of these interventions was delivered by peer mentors, one by trained physicians, one by a nurse, two by an exercise professional, two encouraged patients to prompt their physician, and the final four papers 


\section{Key to figure}

Solid black - study with a control arm and measured data

Black lines = study with multiple intervention arms only and measured data

Solid grey = study with a control arm and self-report data

Grey dots = study with multiple intervention arms only and self-reported data

The height of the column indicates the strength of the study design.

Studies in brackets $=$ concerns identified by quality appraisal

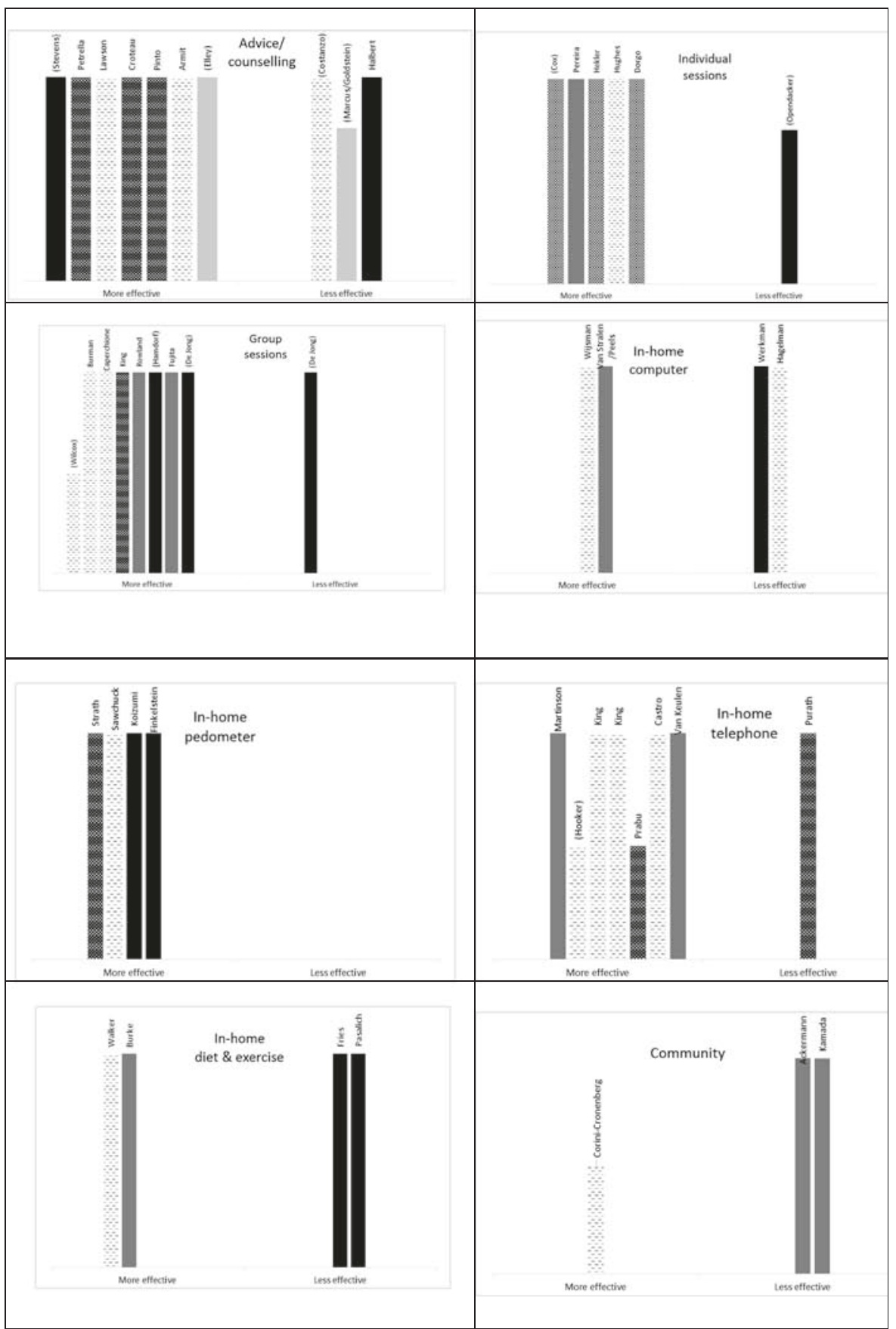

Fig. 3 Harvest plot visual summaries 
examined combined physician and exercise professional input. Seven of the advice/counselling interventions led to positive effects, although there is inconsistency in effectiveness, and only one study had a control group and measured outcomes. Only one study in this category had a follow up of more than 12 months.

\section{Group sessions}

Thirteen papers (nine studies) evaluated group-based programmes provided in community settings [32-44]. All but one of the studies seemed to result in positive effects, thus indicating strength in terms of consistency. Half of the studies had control-group designs and also two used objective measures indicating strength in terms of quality. The evidence for this typology comprised a total of seven studies and therefore suggests strength of evidence not only in terms of design but also in terms of number of studies of group interventions. One of the more effective studies had a follow up of more than 12 months, and all of the group interventions had a follow up period of at least 6 months, also suggesting the effectiveness of these interventions in terms of longer term change.

\section{Individual exercise programmes}

Seven papers (six studies) evaluated individual exercise programmes delivered either at home or in community settings [45-51]. All but one of the six studies reported that interventions were effective, although only one of these had a control arm. The single study (reported in two papers) suggesting less effectiveness was of a lower quality study design, although it had more than 12 months follow up. One of the studies suggesting greater effectiveness had more than 12 months follow up.

\section{In-home telephone interventions}

Nine papers (eight studies) evaluated in-home interventions which were predominantly delivered via the telephone [52-60]. Two of these studies used automated telephone contacts, rather than human coaches, and one paper reported evaluation of a smartphone application. All but one of the interventions appeared to be effective, with three of these having longer follow up periods. The study indicating less effectiveness was of the highest quality, although had only a brief follow up period.

\section{In-home combined diet and exercise interventions}

Six papers (four studies) outlined the results of interventions which targeted lifestyle more generally, and consisted predominantly of materials delivered to the home by post/mail [61-66]. The evidence for this typology was inconsistent, although the best quality studies suggested less effectiveness for PA outcomes.
Home-based interventions providing pedometer/accelerometer While several of the studies reported in other groups included provision of a pedometer as part of the intervention element, four studies evaluated home-based interventions in which the provision of a pedometer/accelerometer was the core component [67-70]. The pedometer-based studies all provided evidence of effectiveness, with three of the studies including measured outcomes (steps) and two using control group designs. This suggests the strength of evidence for pedometer interventions in terms of consistency, although there are only four studies. All these studies had only short or immediate follow up, and therefore do not provide evidence of a longer term impact of these interventions. One found that pedometers did not produce superior results to advice-only interventions.

\section{Computer-based interventions}

Eleven papers (four studies) reported programmes using computers, with all incorporating web-based components $[71-80]$. One of these studies was the only paper we identified which referred to participants as recent retirees [20]. The evidence here was inconsistent, with equal numbers of papers suggesting both more and less effectiveness.

\section{Community-wide initiatives}

One randomised controlled trial aimed to enhance the content of health professional consultations [81]. Two studies evaluated community interventions (a publicity campaign, and free bus passes) $[82,83]$. There was inconsistency in findings.

\section{Discussion}

The majority of studies included in this review reported some intervention effect, although as many studies reported multiple outcomes including perceived change and readiness for change, this may be unsurprising. It is also important to note the tendency for improvement in participants over the period of the study, which may not be related to the intervention. This review echoes earlier studies in finding evidence of effectiveness for a range of interventions intending to increase physical activity in older adults $[1,6,10]$. While group-based, and homebased, with behavioural/activity and/or educational/cognitive components may all be of benefit, there may be differences in longer term effectiveness between components which requires further investigation.

Just under two thirds of the included intervention papers described a theoretical base for their study. These were mainly psychological theories such as stages of change, social cognitive theory, educational theories, or models specific to the motivation of active living. Few papers discussed how the chosen theory impacted on the 
results of their study. The impact of particular theoretical bases for interventions is an area that could be further explored in future research.

We found little evidence specifically referring to interventions during the retirement transition period despite the significance of this period of life change, and association between PA levels and retirement [1]. All but one of the studies we found set wide age ranges for inclusion, or included only populations of retired people. While there was no indication that these interventions would be unsuitable or not effective for people about to retire or recently retired, there is the potential that programmes might have differential effects in this specific population.

Difference in outcome between population sub-groups was rarely mentioned by authors, with little evidence regarding differential impacts on advantaged versus disadvantaged populations. The category of "older adults" used in many studies encompassed individuals at potentially very different stages of the life course, and consequently varying levels of health and physical ability. Further attention to effects on sub-groups of individuals within populations described as "older adults" seems required. Many of the studies were carried out with groups of predominantly female participants, and males may have differing preferences for, or response to particular types of intervention. Future research should explore the reasons for different changes in PA at retirement between different socioeconomic groups, as these may hold the key to what interventions are most effective. If disposable income creates opportunities to be more active, and fatigue from chronic conditions reduces opportunities, then perhaps tackling lifestyle and chronic conditions much earlier than 'retirement' may be most important.

Our study builds on existing reviews by highlighting that evidence is needed regarding optimal interventions around this potentially significant point of life change. The wider evidence base suggests that some types of interventions are likely to be effective in this age group, and there is a striking evidence gap. Previous reviews have examined interventions for older adults more widely. Further development of effective and cost-effective approaches for this population using the evidence we already have, could potentially be a way to target individuals who might not seek out support to be more active in older age, but who might be receptive to an offer of support/activities at the time of retirement. Our review also builds on other reviews which have explored associations between disadvantage and activity $[1,17]$. We highlight the need for greater exploration of differential response to PA interventions in population sub-groups.

The analysis of intervention effectiveness within and across typologies is adversely impacted by the diverse range of outcome measures currently in use. These include those which relate to levels of activity, levels of fitness, psychosocial elements, and correlates of physical activity. If the effectiveness of different interventions is to be compared, there needs to be greater agreement amongst researchers regarding key measures of change. Future studies should endeavour to include objective measures of activity, and not be reliant on self-report data, and include no-intervention rather than comparator intervention control arms, if the true impact of interventions is to be assessed.

\section{Limitations}

Given the lack of studies which identified their population as being about to retire or recently retired, we developed an applicability rating which used age range as a proxy for retirement transition. We acknowledge that the mean or median ages reported by the studies may not reflect the true range of participant ages, and that age does not necessarily equate to retirement. The OECD reports [84] that the statutory retirement age for men and women in all but two member countries is 65 or 67 . However, people may choose (or be forced by health or other circumstances) to retire earlier or later than this. Evidence suggests that people in low SES have more multiple morbidities (physical and mental health) so it may be that by excluding populations with specific conditions we missed studies involving low SES groups.

While the Harvest plot method of presenting the data provides a useful visual summary of effectiveness, we acknowledge that interpretation is complicated by several studies comparing different interventions, and often similar variants of intervention elements. The typology that we have adopted is also only one way of grouping the studies, and we recognise that alternative groupings are possible. This is particularly the case for those interventions with multiple elements.

\section{Conclusions}

Studies are needed which are carried out specifically in adults in the period immediate before or shortly after retirement. This work is needed in order to evaluate whether existing interventions for older adults are most suitable and/or effective in adults who are about to retire or recently retired. Currently it is not known whether or not the retirement transition provides a key opportunity for interventions to effect change in physical activity levels throughout older life, and/or to reduce health inequalities.

\section{Additional file}

Additional file 1: Summary of previous reviews, details of search strategy, and completed quality appraisals for included studies.(DOCX $74 \mathrm{~kb}$ )

\section{Competing interests}

Professor Mountain is a member of the NIHR Health Technology Assessment Commissioning Board, other authors have no conflicting interests to declare. 


\section{Authors' contributions}

SB was a co-applicant on the grant, led the work from the sixth month, and took the lead in drafting the manuscript. MJ was a co-applicant and lead reviewer, LB led the grant application and the work in the initial stages, EH was a co-applicant and contributed to the reviewing process, NP and EG were co-applicants and provided ongoing methodological advice, HB was a co-applicant and carried out the searches, GM was a co-applicant and provided ongoing topic expertise regarding older adults, AD, AT, TP provided ongoing topic expertise regarding physical activity. All authors read and approved the manuscript.

\section{Funding}

This work was funded by the National Institute for Health Research as part of the Public Health Research Programme, (grant number 12/133/20). The views and opinions expressed therein are those of the authors and do not necessarily reflect those of the Health Service and Delivery Research Programme NIHR, NHS or the Department of Health.

\section{Author details}

'School of Health and Related Research, University of Sheffield, Regent Court, 30 Regent Street, Sheffield S14DA, UK. ${ }^{2}$ Institute of Applied Health Research, College of Medical and Dental Sciences, University of Birmingham, Birmingham, UK. ${ }^{3}$ Peninsula Schools of Medicine \& Dentistry, Plymouth University, Plymouth, UK. ${ }^{4}$ School of Human Movement and Nutrition Sciences, University of Queensland, Brisbane, Australia.

\section{Received: 3 November 2015 Accepted: 26 January 2016}

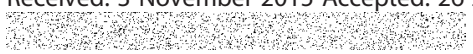

\section{References}

1. Barnett I, Ogilvie D, Guell C. Physical activity and transitioning to retirement: a systematic review. Am J Prev Med. 2012;43:329-36.

2. Emmerson $C$, Heald $K$, Hood $A$. The changing face of retirement: future patterns of work, health, care and income among the older population. London: Institute for Fiscal Studies; 2014.

3. Bélanger M, Townsend N, Foster C. Age-related differences in physical activity profiles of English adults. Prev Med. 2011;52:247-9.

4. Allender S, Hutchinson L, Foster C. Life-change events and participation in physical activity: a systematic review. Health Promot Int. 2008;23:160-72. doi:10.1093/heapro/dan012.

5. Chase JA. Physical activity interventions among older adults: a literature review. Res Theory Nurs Pract. 2013;27:53-80.

6. Conn VS, Valentine JC, Cooper HM. Interventions to increase physical activity among aging adults: a meta-analysis. Ann Behav Med. 2002;2:190-200.

7. Conn VS, Minor MA, Burks KJ, Rantz MJ, Pomeroy SH. Integrative review of physical activity intervention research with aging adults. J Am Geriatr Soc. 2003:51:1159-68.

8. Engberg E, Alen M, Kukkonen-Harjula K, Peltonen JE, Tikkanen HO, Pekkarinen $\mathrm{H}$. Life events and change in leisure time physical activity: a systematic review. Sports Med. 2012;42:433-47.

9. Frost H, Haw S, Frank J. Promoting health and wellbeing in later life: interventions in primary care and community settings. Edinburgh: Scottish Collaboration for Public Health Research and Policy; 2010.

10. Hobbs N, Godfrey A, Lara J, Errington L, Meyer TD, Rochester L, et al. Are behavioral interventions effective in increasing physical activity at 12 to 36 months in adults aged 55 to 70 years? A systematic review and meta-analysis. BMC Med. 2013;11:75. doi:10.1186/1741-7015-11-75.

11. King AC, Rejeski WJ, Buchner DM. Physical activity interventions targeting older adults. A critical review and recommendations. Am J Prev Med. 1998;15:316-33.

12. Muller AM, Khoo S. Non-face-to-face physical activity interventions in older adults: a systematic review. Inter J Behav Nutrition Phys Activ. 2014;11:35. doi:10.1186/1479-5868-11-35.

13. Taylor A, Cable N, Faulkner G, Hillsdon M, Narici M, Van Der Bij A. Physical activity and older adults: a review of health benefits and the effectiveness of interventions. J Sports Sci. 2004;22:703-25.

14. Van der Bij AK, Laurant MGH, Wensing M. Effectiveness of physical activity interventions for older adults - a review. Am J Prev Med. 2002;22(2):120-33.

15. Von Bonsdorff M, Rantanen T. Benefits of formal voluntary work among older people. A Review. Ageing Clin Exp Res. 2011;23:162-9.
16. Wilson DM, Palha P. A systematic review of published research articles on health promotion at retirement. J Nurs Scholar. 2007:4:330-7. doi:10.1111/j.1547-5069.2007.00189.x.

17. Barnett I, Guell C, Ogilvie D. The experience of physical activity and the transition to retirement: a systematic review and integrative synthesis of qualitative and quantitative evidence. Int J Behav Nutr Phys Act. 2012;9:97. doi:10.1186/1479-5868-9-97.

18. Ogilvie D, Fayter D, Petticrew M, Sowden A, Thomas S, Whitehead M, et al. The harvest plot: A method for synthesising evidence about the differential effects of interventions. BMC Med Res Methodol. 2008;8. doi:10.1186/1471-2288-8-8.

19. Cochrane Collaboration. Cochrane Handbook for Systematic Reviews of Interventions, Cochrane Collaboration, Version 5.1.0 March 2011. Available from http://www.cochrane-handbook.org. Accessed 4/9/12.

20. Werkman A, Hulshof PJ, Stafleu A, Kremers SP, Kok FJ, Schouten EG, et al. Effect of an individually tailored one-year energy balance programme on body weight, body composition and lifestyle in recent retirees: a cluster randomised controlled trial. BMC Public Health. 2010;10:110. doi:10.1186/1471-2458-10-110.

21. Armit CM, Brown WJ, Ritchie CB, Trost SG. Promoting physical activity to older adults: a preliminary evaluation of three general practice-based strategies. J Sci Med Sport. 2005;8:446-50.

22. Costanzo C, Walker SN. Incorporating self-efficacy and interpersonal support in an intervention to increase physical activity in older women. Women Health. 2008;47:91-108.

23. Croteau KA, Suresh V, Farnham E. Efficacy of using physical activity mentors to increase the daily steps of older adults in the primary care setting: a pilot study. J Aging Phys Act. 2014;22:16-24.

24. Elley CR, Kerse N, Arroll B, Robinson E. Effectiveness of counselling patients on physical activity in general practice: cluster randomised controlled trial. BMJ. 2003;326:7393.

25. Goldstein MG, Pinto BM, Marcus BM, Lynn H, Jette AM, Rakowski W, et al. Physician-based physical activity counseling for middle-aged and older adults: a randomized trial. Ann Behav Med. 1999:21:40-7.

26. Halbert JA, Silagy CA, Finucane PM, Withers RT, Hamdorf PA. Physical activity and cardiovascular risk factors: effect of advice from an exercise specialist in Australian general practice. Med J Aust. 2000;173:84-7.

27. Lawton BA, Rose SB, Elley CR, Dowell AC, Fenton F, Simon A, et al. Exercise on prescription for women aged 40-74 recruited through primary care: two year randomised controlled trial. BMJ 2008. 337:a2509.

28. Marcus B, Goldstein M, Jette J, Simkin-Silverman L, Pinto B, Milan FB, et al. Training physicians to conduct physical activity counselling. Prev Med. 1997;26:382-8

29. Petrella RJ, Lattanzio CN, Shapiro S, Overend T. Improving aerobic fitness in older adults: effects of a physician-based exercise counseling and prescription program. Can Fam Physician. 2010;56:e191-200.

30. Pinto BM, Goldstein MG, Ashba J, Sciamanna CN, Jette A. Randomized controlled trial of physical activity counseling for older primary care patients. Am J Prev Med. 2005:29:247-55.

31. Stevens W, Hillsdon M, Thorogood M, McArdle D. Cost-effectiveness of a primary care based physical activity intervention in 45-74 year old men and women: a randomised controlled trial. Br J Sports Med. 1998:32:236-41.

32. Burman MP, Giacobbi PR, Dzierzewski JM, Morgan A, Aiken CS, McCrae BL, et al. Peer volunteers improve long-term maintenance of physical activity with older adults: a randomized controlled trial. J Phys Act Health. 2011;8 Suppl 2:S257-66.

33. Caperchione $\mathbf{C}$, Mummery $\mathrm{K}$. The utilisation of group process strategies as an intervention tool for the promotion of health-related physical activity in older adults. Act Adapt Aging. 2006;30:29-45.

34. de Jong J, Lemmink KAPM, Stevens $M$, de Greef MHG, Rispens P, King AC, et al. Six-month effects of the Groningen active living model (GALM) on physical activity, health and fitness outcomes in sedentary and underactive older adults aged 55-65. Patient Educ Couns. 2006;62:132-41.

35. de Jong J, Lemmink KA, King AC, Huisman M, Stevens M. Twelve-month effects of the Groningen active living model (GALM) on physical activity, health and fitness outcomes in sedentary and underactive older adults aged 55-65. Patient Educ Couns. 2007:66:167-76.

36. Fujita KR, Nagatomi A, Hozawa T, Ohkubo K, Sato Y, Anzai C, et al. Effects of exercise training on physical activity in older people: a randomized controlled trial. J Epidemiol. 2003;13:120-6. 
37. Hamdorf PA, Withers RT, Penhall RK, Haslam MV. Physical training effects on the fitness and habitual activity patterns of elderly women. Arch Phys Med Rehabil. 1992;73:603-8.

38. Hamdorf PA, Withers RT, Penhall RK, Plummer JL. A follow-up study on the effects of training on the fitness and habitual activity patterns of 60-to 70-year-old women. Arch Phys Med Rehabil. 1993;74:473.

39. King AC, Friedman R, Marcus B, Castro C, Forsyth L, Napolitano M, et al. Harnessing motivational forces in the promotion of physical activity: the Community Health Advice by Telephone (CHAT) project. Health Ed Res. 2002;17:627-36.

40. Rowland L, Dickinson EJ, Newman P, Ford D, Ebrahim S. Look After Your Heart programme: impact on health status, exercise knowledge, attitudes, and behaviour of retired women in England. J Epidemiol Community Health. 1994;48:123-8.

41. Wilcox S, Dowda M, Leviton LC, Bartlett-Prescott J, Bazzarre T, Campbell-Voytal $K$, et al. Active for life - final results from the translation of two physical activity programs. Am J Prev Med. 2008;35:340-51.

42. Wilcox S, Dowda M, Wegley S, Ory MG. Maintenance of change in the active-for-life initiative. Am J Prev Med. 2009;37:501-4.

43. Wilcox S, Dowda M, Dunn A, Ory MG, Rheaume C, King AC. Predictors of increased physical activity in the active for life program. Prev Chronic Dis. 2009;6(1):A25.

44. Wilcox S, Dowda M, Griffin SF, Rheaume C, Ory MG, Leviton L, et al. Results of the first year of active for life: translation of 2 evidence-based physica activity programs for older adults into community settings. Am J Public Health. 2006:96:1201-9.

45. Cox KL, Burke V, Beilin LJ, Derbyshire AJ, Grove JR, Blanksby BA, et al. Short and long-term adherence to swimming and walking programs in older women-the Sedentary Women Exercise Adherence Trial (SWEAT 2). Prev Med. 2008:46:511-7.

46. Dorgo SG, King AC, Brickey GD. The application of peer mentoring to improve fitness in older adults. J Aging Phys Act. 2009;17:344-61.

47. Hekler EB, Castro CM, Buman MP, King AC. The CHOICE study: a "taste-test" of utilitarian vs. leisure walking among older adults. Health Psychol. 2012;31:126-9

48. Hughes SL, Seymour RB, Campbell RT, Whitelaw N, Bazzarre T. Best-practice physical activity programs for older adults: findings from the National Impact study. Am J Public Health. 2009:99:362-8.

49. Opdenacker J, Delecluse C, Boen F. A 2-year follow-up of a lifestyle physical activity versus a structured exercise intervention in older adults. J Am Geriatr Soc. 2011;59:1602-11

50. Opdenacker J, Boen F, Coorevits N, Delecluse C. Effectiveness of a lifestyle intervention and a structured exercise intervention in older adults. Prev Med. 2008;46:518-24.

51. Pereira MA, Kriska AM, Day RD, Cauley JA, LaPorte RE, Kuller LH. A randomized walking trial in postmenopausal women: effects on physical activity and health 10 years later. Arch Intern Med. 1998;158:1695-701.

52. Castro CM, King AC, Brassington GS. Telephone versus mail interventions for maintenance of physical activity in older adults. Health Psychol. 2001;20:438.

53. Hooker SP, Seavey W, Weidmer CE, Harvey DJ, Stewart AL, Gillis DE, et al. The California active aging community grant program: translating science into practice to promote physical activity in older adults. Ann Behav Med. 2005;29:155-65.

54. King AC, Friedman R, Marcus M, Castro C, Napolitano M, Ahn D, et al. Ongoing physical activity advice by humans versus computers: the Community Health Advice by Telephone (CHAT) trial. Health Psychol. 2007;26:718.

55. King AC, Hekler EB, Grieco LA, Winter SJ, Sheats JL, Buman MP, et al. Harnessing different motivational frames via mobile phones to promote daily physical activity and reduce sedentary behavior in aging adults. PLOS ONE. 2013:8:e62613.

56. Martinson BC, Sherwood NE, Crain AL, Hayes MG, King AC, Pronk NP, et al. Maintaining physical activity among older adults: 24-month outcomes of the Keep Active Minnesota randomized controlled trial. Prev Med. 2010;51:37-44

57. Martinson BC, Crain AL, Sherwood NE, Hayes M, Pronk NP, O'Connor PJ. Maintaining physical activity among older adults: six month outcomes of the Keep Active Minnesota randomized controlled trial. Prev Med. 2008:46:111-9.

58. Prabu D, Buckworth J, Pennell ML, Katz ML, DeGraffinreid CR, Paskett E. A walking intervention for postmenopausal women using mobile phones and interactive voice response. Anonymous. Anonymous. J Telemed Telecare. 2012;18:20-5.

59. Purath J, Keller CS, McPherson S, Ainsworth B, Purath J, Keller CS, et al. A randomized controlled trial of an office-based physical activity and physical fitness intervention for older adults. Geriatr Nurs. 2013;34:204-11.

60. Van Keulen HM, Mesters I, Ausems M, Van Breukelen G, Campbell M, Resnicow K, et al. Tailored print communication and telephone motivationa interviewing are equally successful in improving multiple lifestyle behaviors in a randomized controlled trial. Ann Behav Med. 2011;41:104-18.

61. Burke L, Lee AH, Jancey J, Xiang L, Kerr DA, Howat PA, et al. Physical activity and nutrition behavioural outcomes of a home-based intervention program for seniors: a randomized controlled trial. Int J Behav Nutr Phys Act. 2013;10:14. doi:10.1186/1479-5868-10-14.

62. Fries JF, Bloch DA, Harrington $\mathrm{H}$, Richardson N, Beck R. Two year results of a randomized controlled trial of a health promotion program in a retiree population: the Bank of America Study. Am J Med. 1993;94:455-62.

63. Fries JF, Tilton-Fries S, Percell $\mathrm{CL}$, Harrington $\mathrm{H}$. Health Risk Changes with a low-cost individual health promotion program: effects at up to 30 months. Am J Health Promot. 1993;6:363-71.

64. Pasalich M, Lee AH, Jancey J, Burke L, Howat P. Sustainability of a physical activity and nutrition program for seniors. J Nutr Health Aging. 2013;17:486-491.67.

65. Walker SN, Pullen $\mathrm{CH}$, Boeckner L, Hageman PA, Hertzog M, Oberdorfer MK, et al. Clinical trial of tailored activity and eating newsletters with older rural women. Nurs Res. 2009;58:74-85.

66. Walker SN, Pullen CH, Hageman PA, Boeckner LS, Hertzog M, Oberdorfer MK, et al. Maintenance of activity and eating change after a clinical trial of tailored newsletters with older rural women. Nurs Res. 2010:59:311-21.

67. Finkelstein EA, Brown DS, Brown DR, Buchner DM. A randomized study of financial incentives to increase physical activity among sedentary older adults. Prev Med. 2008;47:182-187.70.

68. Koizumi D, Rogers NL, Rogers ME, Islam MM, Kusunoki M, Takeshima N. Efficacy of an accelerometer-guided physical activity intervention in community-dwelling older women. J Phys Act Health. 2009:6:467-74.

69. Sawchuk CN, Charles S, Wen Y, Goldberg J, Forquera R, Roy-Byrne P, et al. A randomized trial to increase physical activity among native elders. Prev Med. 2008;47:89-94.

70. Strath SJ, Swartz AM, Parker SJ, Miller NE, Grimm EK, Cashin SE. A pilot randomized controlled trial evaluating motivationally matched pedometer feedback to increase physical activity behavior in older adults. J Phys Act Health. 2011:8:S267-74.

71. Hageman PA, Walker SN, Pullen CH. Tailored versus standard internet-delivered interventions to promote physical activity in older women. J Geriatr Phys Ther. 2005:28(1):28-33.

72. Irvine AB, Gelatt VA, Seeley JR, Macfarlane P, Gau JM. Web-based intervention to promote physical activity by sedentary older adults: randomized controlled trial. J Med Internet Res. 2013:15:e19. doi:10.2196/jmir.2158.

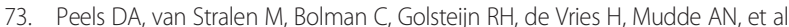
Development of web-based computer-tailored advice to promote physical activity among people older than 50 years. J Med Internet Res. 2012;14:e39.

74. Peels DA, Bolman C, Golsteijn RHJ, de Vries H, Mudde AN, van Stralen MM, et al. Differences in reach and attrition between web-based and print-delivered tailored interventions among adults over 50 years of age: clustered randomized trial. J Med Internet Res. 2012:14:146-58.

75. Peels DA, Bolman C, Golsteijn RHJ, de Vries H, Mudde AN, van Stralen MM, et al. Long-term efficacy of a printed or a web-based tailored physical activity intervention among older adults. Int J Behav Nutr Phys Act. 2013;10:104. doi:10.1186/1479-5868-10-104.

76. van Stralen M, de Vries H, Mudde AN, Bolman C, Lechner L. Efficacy of two tailored interventions promoting physical activity in older adults. Am J Prev Med. 2009:37:405-17.

77. van Stralen M, de Vries H, Bolman C, Mudde AN, Lechner L. Exploring the efficacy and moderators of two computer-tailored physical activity interventions for older adults: a randomized controlled trial. Ann Behav Med. 2010;39:139-50.

78. van Stralen M, de Vries H, Mudde AN, Bolma C, Lechner L. The long-term efficacy of two computer-tailored physical activity interventions for older adults: main effects and mediators. Health Psychol. 2011;30:442-52.

79. van Stralen $M$, de Vries $H$, Mudde AN, Bolman C, Lechner L. The working mechanisms of an environmentally tailored physical activity intervention for 
older adults: a randomized controlled trial. Int J Behav Nutr Phys Act. 2009;6:83. doi:10.1186/1479-5868-6-83.

80. Wijsman CA, Westendorp RGJ, Verhagen EALM, Catt M, Slagboom E, de Craen AJM, et al. Effects of a web-based intervention on physical activity and metabolism in older adults: randomized controlled trial. J Med Internet Res. 2013;15:e233. doi:10.2196/jmir.2843.

81. Ackermann RT, Deyo RA, LoGerf JP. Prompting primary providers to increase community exercise referrals for older adults: a randomized trial. J Am Geriatr Soc. 2005;53:283-9.

82. Kamada MJ, Kitayuguchi Inoue S, Ishikawa Y, Nishiuchi H, Okada S. A community-wide campaign to promote physical activity in middle-aged and elderly people: a cluster randomized controlled trial. Int J Behav Nutr Phys Act. 2013;10:44 doi:10.1186/1479-5868-10-44.

83. Hoogendoom WE, van Poppel MN, Bongers PM, Koes BW, Bouter LM. Physical load during work and leisure time as risk factors for back pain. Scand J Work Environ Health. 1999;25:387-403.

84. OECD. Pensions at a Glance: OECD and G20 Indicators. OECD Publishing 2013. http://dx.doi.org/10.1787/pension_glance-2013-en. Last accessed 25 March 2015.

Submit your next manuscript to BioMed Central and we will help you at every step:

- We accept pre-submission inquiries

- Our selector tool helps you to find the most relevant journal

- We provide round the clock customer support

- Convenient online submission

- Thorough peer review

- Inclusion in PubMed and all major indexing services

- Maximum visibility for your research

Submit your manuscript at www.biomedcentral.com/submit
Biomed Central 